\title{
FINANCIAMENTO PARTIDÁRIO PARA ELEIÇÕES MAJORITÁRIAS: estratégias eleitorais nas campanhas brasileiras de 2012 e 2014
}

\author{
Mércia Alves ${ }^{1}$
}

\section{Resumo:}

No Brasil, os partidos políticos disputam eleições em três níveis de forma autônoma: Federal, nos estados e municípios. Candidatos e organizações partidárias captam recursos para financiamento das suas campanhas eleitorais de forma autônoma, e a legislação brasileira permite que sejam arrecadados valores de origem privada, individual e que as direções partidárias nacionais, estaduais e municipais invistam em seus candidatos. Assim, o objetivo deste trabalho é analisar a distribuição vertical de recursos para financiamento de campanhas eleitorais majoritárias no Brasil. Para tanto, serão utilizados relatórios de prestação de contas oficiais elaboradas pelos partidos referentes às eleições municipais de 2012 e às eleições gerais de 2014. A hipótese é que o volume de recursos financeiros investidos pelas direções partidárias nas campanhas eleitorais de seus candidatos é maior de acordo com a avaliação das chances eleitorais dos mesmos. Argumenta-se que candidatos governistas recebem mais dinheiro de suas legendas se comparados aos candidatos opositores.

Palavras-Chave: Partidos e Eleições, Eleitorais Majoritárias, Campanhas Eleitorais Financiamento do Sistema Eleitoral, Estratégias Eleitorais.

\begin{abstract}
:
In Brazil, the political parties compete elections on three levels autonomously: Federal, in states and municipalities. Candidates and party organizations raise funds autonomously to finance their election campaigns, and Brazilian law allows them to be collected amounts from private, individual source and that national, state and local party leaders invest in their candidates. The aim of this study is to analyze the vertical distribution of funds to finance majoritarian electoral campaigns in Brazil. Therefore, provision of official financial reports prepared by the parties concerning the municipal elections of 2012 will be used, and the general elections of 2014. The assumption is that the volume of funds invested by the party leaders in their candidates' campaigns is greater according to the assessment of the electoral their chances. It is discussed that pro-government candidates receive more money from their captions compared to the challenging candidates.
\end{abstract}

Keywords: Parties and Elections, Electoral Majority, Election Campaign Financing the Electoral System, Electoral Strategies.

\footnotetext{
${ }^{1}$ Doutoranda em Ciência Política (PPGPOL/UFSCar); membro do grupo de pesquisa Comunicação Política, Partidos e Eleições da UFSCar e do NEAMP - Núcleo de Estudos em Arte, Mídia e Política PUC/SP. Bolsista da FAPESP. E-mail:mercia_f.alves@hotmail.com.
} 


\section{Introdução}

No Brasil, o desenho federativo é essencial para a definição das estratégias eleitorais dos partidos políticos. São três níveis de governo instituídos constitucionalmente como entes federados desde 1998, eleitoralmente autônomos. Quando se trata dos poderes executivos, os cargos de Presidente da República e Governo dos Estados são disputados de forma casada aos legislativos federal e estadual, em eleições gerais, que desde as eleições de 1994, são disputadas a cada quatro anos. Para o executivo e legislativo dos municípios, são realizadas eleições intermediárias, a cada quatro anos, intercaladas às gerais.

É apenas para a eleição ao cargo de Presidência da República, que os partidos e candidatos competem pela preferência eleitoral a nível nacional. Para todos os demais cargos eletivos, os partidos disputam o apoio popular em territórios distintos, seja nos 26 estados e o Distrito Federal seja nos 5.570 municípios, que compõem as unidades federativas brasileiras. Em outras palavras, os partidos políticos brasileiros competem por votos em contextos políticos, sociais e econômicos distintos.

Ainda no caso brasileiro, cada um dos partidos políticos quanto à sua estrutura organizacional é composto de diretórios nacionais, estaduais e municipais, ou ainda por comissões provisórias no caso dos municípios (BRAGA e PIMENTEL, 2007). Esses aspectos refletem na organização partidária, mais flexível e autônoma para lançar candidatos e realizar as suas campanhas (BOLLEYER, 2012), inclusive quanto se trata da arrecadação de recursos financeiros para tanto.

O perfil previsto em lei para o financiamento de campanhas no Brasil é misto, onde estão aptos a contribuir, pessoas físicas, empresas, empreiteiras, instituições bancárias e financeiras nacionais ou estrangeiras, além do autofinanciamento e do investimento dos partidos políticos. ${ }^{2}$ Portanto, tem-se nos diretórios partidários uma fonte de recursos financeiros para candidatos. E como parte das estratégias políticas e eleitorais dos partidos, o investimento em determinadas campanhas eleitorais, em detrimento de outras.

Assim, objetivo central deste trabalho é analisar a distribuição vertical de recursos para financiamento de campanhas eleitorais majoritárias no Brasil. Elucidar a forma como as organizações partidárias destinam recursos financeiros para as campanhas de seus candidatos a

\footnotetext{
2 NOTA EDITORIAL: o presente artigo foi recebido pela revista em 21/05/2016 e trata das eleições de 2012 e 2014. Assim sendo, fazemos a ressalva de que em sua leitura deve-se desconsiderar as alterações da Minirreforma Eleitoral de 2015, Lei $N^{\circ} 13.165$, de 29 de setembro de 2015, e da reforma mais recente, Lei $\mathrm{N}^{\circ} 13.488$, de 6 de outubro de 2017, sobretudo no tocante ao financiamento de campanhas por pessoas jurídicas.
} 
nível estadual e municipal/local. Essa distribuição pode ser realizada de três formas: para as eleições governamentais, dos diretórios nacionais e estaduais/distritais e locais para as campanhas dos candidatos, e por meio de comitês eleitorais constituídos especificamente para gerenciar finanças eleitorais. Da mesma forma, para eleições municipais dos diretórios nacionais, estaduais/distritais e municipais, além dos comitês.

Para tanto, serão utilizados relatórios de prestação de contas oficiais elaboradas pelos partidos referentes às eleições municipais de 2012 e às eleições gerais de 2014. Como unidades de análise, foram selecionados os cinco estados brasileiros com maior colégio eleitoral para as eleições de 2014 e as suas respectivas capitais para 2012. O colégio eleitoral brasileiro em 2014 foi de 142.822.038 aptos a votar, somado o número de eleitores que votaram fora do país, 354.184. A tabela abaixo aponta, segundo dados do $\mathrm{TSE}^{3}$, para os estados brasileiros com os maiores colégios eleitorais no Brasil.

\begin{tabular}{l|l|l}
\multicolumn{2}{c}{ Tabela 01- Maiores colégios eleitorais brasileiros em } \\
$\mathbf{2 0 1 4}$ por estado \\
\hline \multirow{2}{*}{ Estado } & \multicolumn{2}{|c}{ Maiores colégio eleitorais } \\
\cline { 2 - 3 } & Absoluto & Percentual \\
\hline São Paulo & 31.998 .429 & 22,4 \\
\hline Minas Gerais & 15.248 .680 & 10,6 \\
\hline Rio de Janeiro & 12.141 .143 & 8,5 \\
\hline Bahia & 10.185 .417 & 7,1 \\
\hline Rio Grande do Sul & 8.392 .033 & 5,8 \\
\hline Fonte: Elaboração Própria
\end{tabular}

Tem-se então, que para atender aos objetivos propostos de compreender a distribuição vertical de recursos para financiamento de campanhas eleitorais majoritárias no Brasil, foram selecionados: a) as campanhas eleitorais de cada um dos cinco estados com maior colégio eleitoral no Brasil em 2014, a saber: São Paulo, Minas Gerais, Rio de Janeiro, Bahia e Rio Grande de Sul e; b) as campanhas eleitorais de 2012 em cada uma das capitais dos estados citados, respectivamente, São Paulo, Belo Horizonte, Rio de Janeiro, Salvador e Porto Alegre.

Serão analisadas as duas principais campanhas em cada um dos casos, um total de 10 campanhas em 2014 para os governos estaduais, e 10 campanhas para as prefeituras em 2012. Entende-se por principais campanhas aquelas que alcançaram os maiores percentuais de votos,

\footnotetext{
${ }^{3}$ Tribunal Superior Eleitoral

${ }^{4} \mathrm{O}$ percentual é referente ao colégio eleitoral brasileiro.
} 
independente de turno único ou segundo turno ${ }^{5}$, e dos partidos que alcançaram esses índices. Apresenta-se então, uma análise que não privilegia determinadas legendas partidárias, mas que busca entender aspectos das estratégias eleitorais dos partidos como um todo.

Questiona-se, a partir disso, como se dá a distribuição vertical de recursos para financiamento de campanhas eleitorais majoritárias para os governos estaduais e municipais no Brasil. A hipótese é que o volume de recursos financeiros investidos pelas direções partidárias nas campanhas eleitorais de seus candidatos é maior de acordo com a avaliação das chances eleitorais dos mesmos. Argumenta-se assim, que candidatos governistas recebem mais dinheiro de suas legendas se comparados aos candidatos opositores.

A partir dos casos específicos, propõe-se observar se a participação dos partidos políticos no montante de recursos arrecadados para a realização das campanhas eleitorais é significativo e, por consequência, o quanto os candidatos locais são financeiramente dependentes das suas legendas para organização de campanhas. No caso de partidos políticos financeiramente participativos, quais os diretórios em cada um dos casos mais investem nos seus candidatos?

Finalmente, há algum grau de concentração ou dispersão de recursos entre as candidaturas dos partidos? Qual a proporção de investimento bem sucedido? É possível apontar tendências em relação ao investimento partidário para campanhas estaduais e locais no Brasil. E assim, elucidar para estratégias relacionadas à distribuição dos recursos financeiros para campanhas eleitorais, dado que partidos políticos em determinada eleição, podem "escolher" investir ou não nas campanhas dos candidatos aos governos estaduais e às prefeituras municipais; e que o dinheiro é um recurso fundamental para a realização e o sucesso de campanhas eleitorais no Brasil.

O texto está organizado da seguinte forma: primeiro uma reflexão do desenho institucional brasileiro, que gera constrangimentos à atuação dos partidos políticos na arena eleitoral. Posteriormente, são discutidos alguns dos aspectos fundamentais sobre o financiamento das campanhas eleitorais no Brasil, a importância central do dinheiro para o financiamento das atividades de campanha. Finalmente, são apresentados os dados das eleições municipais e estaduais, conforme recorte proposto.

\footnotetext{
${ }^{5}$ No Brasil, as eleições majoritárias para cargos executivos são definidas no primeiro turno quando o partido alcança a maioria absoluta dos votos, quando não, é disputado um segundo turno com os dois mais votados.
} 


\section{Desenho institucional, organização e atuação dos partidos na arena eleitoral}

Diferentes desenhos institucionais influenciam a organização dos partidos políticos, o comportamento das elites políticas, e constituem estruturas de incentivos distintas (SAMUELS e SHUGART, 2010). No Brasil, uma República Federativa, os entes federados são dotados de competências administrativas próprias, independência político-partidária e eleitoral para funções específicas (KERBAUY, 2001). Assim, em períodos eleitorais os partidos políticos atuam em diferentes contextos, e empreendem esforços de forma descentralizada para coordenar as estratégias entre os níveis em que competem por cargos eleitorais.

O tema dos impactos do desenho institucional sobre a organização dos partidos na literatura brasileira passa por temas como, a influência mutua entre os resultados das eleições gerais e intermediárias (SOARES e BURNI, 2013), o processo de escolha de candidatos que pode ser mais ou menos centralizado (GUARNIERI, 2011), a filiação de novos membros e a definição de coligações eleitorais, que podem sofrer mais ou menos constrangimentos, dependente do nível da competição eleitoral (DANTAS, 2007), e o padrão dessas coligações (CARREIRÃO, 2014; TELLES, LOURENÇO e STORNI, 2009).

Modelos federalistas diferem principalmente quanto ao seu grau de centralização e descentralização, paralelo à autonomia dos entres federados. Tem-se uma separação clara ou alguma interposição de poderes entre as ordens de governo instituídas constitucionalmente (ANDERSON, 2009). No Brasil, a partir da constituição de 1988, os municípios passaram a entes federados dotados de determinada autonomia institucional e competências, antes alocadas às administrações estadual e federal. O que significou um importante passo para ampliação do escopo da gestão local.

Outra importante dimensão institucional a ser considerada na discussão sobre as características do Federalismo é o sistema eleitoral, uma vez que as suas características produzem efeitos diversos no sistema político, sobretudo, na organização dos partidos políticos (CHANDLER e CHANDLER, 1987; MELO e PEREIRA, 2013). No Brasil, um presidencialismo multipartidário de lista aberta, que combina o voto majoritário para eleger o poder executivo nos três níveis de governo e o Senado Federal, e proporcional para escolha das casas legislativas, o maior efeito é a segmentação do número de legendas partidárias.

Outros fatores que incidem sobre o número de partidos políticos: a legislação mais ou menos restritiva, o grau de institucionalidade do sistema partidário, além da existência de divisões sociais e grupos com interesses e demandas políticas distintas, podem ser fatores para 
mobilização de novas legendas (NICOLAU, 2012). Assim, as federações geralmente têm sua competição eleitoral estruturada por mais de dois partidos, e apesar de haver exceções, os partidos que disputam na esfera federal também estão presentes e influenciam as unidades constitutivas (ANDERSON, 2009).

Das questões sobre o sistema eleitoral em uma Federação, destaca-se complexidade da atuação dos partidos políticos nos períodos eleitorais, ao lançar candidatos para três níveis de governo, buscando apoio em bases eleitorais distintas, com demandas muito próprias. Portanto, o argumento aqui ressaltado caminha na linha de Carty (2004) e Bolleyer (2012), para os quais as variáveis dos contextos locais são essenciais para entender as dinâmicas partidárias e eleitorais. Isso, desde a institucionalização do partido político no caso dos municípios ${ }^{6}$, ao recrutamento de candidatos, o estabelecimento de coligações, e a avaliação das características sociopolíticas e econômicas locais, e as chances eleitorais, de que depende a arrecadação de recursos financeiros.

O principal argumento a ser ressaltado nesse sentido, e de que dependem os objetivos deste trabalho, é que o sistema partidário brasileiro é multidimensional e descentralizado, e que a atuação dos partidos na arena eleitoral pode ser mais ou menos integrada entre as três esferas de poder. A questão da distribuição vertical de recursos financeiros, das instâncias partidárias superiores às campanhas dos candidatos nas esferas estaduais e municipais, passa por esse tema.

\section{Origem de recursos financeiros para campanhas eleitorais}

O tema do financiamento de campanhas está relacionado aos recursos que partidos e candidatos utilizam para formulação das suas campanhas eleitorais. Trata-se do dinheiro que se deve arrecadar para gastos com atividades que tem por finalidade "convencer eleitores a votarem a favor de determinado projeto político, partido ou candidato" (SPECK, 2006, p. 153). As primeiras regras para o uso desses recursos por partidos e candidatos no Brasil datam da década de 1950 e essas somente estipulavam tetos para esses gastos. É apenas a partir da reabertura política em meados da década de 1980 que a competição política ganha relevância e

\footnotetext{
${ }^{6}$ Cada partido político brasileiro quanto à sua estrutura organizacional - dada a ordem federativa de distribuição de poder já ressaltada - pode ser composto de diretórios municipais, ou comissões provisórias em todas as cidades brasileiras. Diretórios partidários em comparação às comissões são dotados de uma estrutura organizacional mais complexa, instaurados após comissão. De diferente forma, as comissões não são permanentes, podendo na ausência de homologação ser destituídas. Entretanto, ambas as formas de organização em nada se diferenciam quanto às prerrogativas eleitorais (BRAGA e PIMENTEL, 2013).
} 
que a questão do financiamento das campanhas chama a atenção, uma vez que a cada pleito o volume de dinheiro injetados em campanhas é maior (SPECK, 2012).

São muitos os motivos que levaram ao encarecimento gradual das campanhas eleitorais brasileiras. Entre eles, o acirramento das disputas eleitorais e o grande número de partidos políticos que aumenta o grau de incerteza durante as eleições; o uso da televisão como principal canal de comunicação entre partidos/candidatos e eleitores, e o processo de modernização e profissionalização das campanhas eleitorais (FARREL, 1996). Referem-se aos profissionais especializados, contratados pelos partidos para desenvolvimento de técnicas específicas e para utilização de ferramentas modernas nas campanhas eleitorais (ALVES, 2015).

É a partir da Lei das Eleições de 1997 que foi permitida a doação de recursos financeiros de pessoas físicas e jurídicas para campanhas no Brasil, até então, as despesas eleitorais eram de responsabilidade única dos partidos. No caso de pessoa física, é permitida a doação de até $10 \%$ dos rendimentos brutos do ano anterior à eleição, para pessoa jurídica, $2 \%$ do faturamento. ${ }^{7}$ As doações podem ser efetuadas para um ou mais partidos e candidatos, e a utilização desses recursos, assim como a prestação de contas prevista por lei, é de responsabilidade partidária.

O Estado não investe diretamente em campanhas eleitorais no Brasil. Entretanto, destina recursos indiretamente de duas formas: a primeira, a partir do fundo partidário ${ }^{8}$ e a segunda, pela concessão do $\mathrm{HGPE}^{9}$ e os spots ${ }^{10}$ no rádio e na televisão. Ambos representam dois dos principais recursos políticos disponíveis para os partidos no período eleitoral, uma vez que a compra de espaço nos meios de comunicação de massa é vetada aos partidos, e a TV ainda representa o principal meio pelo qual os eleitores identificam os candidatos (VEIGA, 2002); Em paralelo, o fundo partidário é para os partidos, sua principal fonte de renda fixa, apesar do indicativo de que a maior parte da origem dos recursos que financiam as campanhas é privada (MANCUSO, 2015).

A importância de compreender a origem dos recursos financeiros para campanhas se dá porque existe, de forma geral, uma relação direta entre volume de dinheiro gasto para atividades

\footnotetext{
${ }^{7}$ Quanto ao financiamento por pessoas jurídicas ver a nota $\mathrm{N}^{\mathrm{o}} 2$, NOTA EDITORIAL.

${ }^{8}$ Fundo de assistência financeira destinado a todos os partidos políticos com registro no TSE, segundo Lei $\mathrm{n}^{\circ}$ 9.096, de 19 de setembro de 1995, alterada pela Lei no 11.459/2009; Capítulo II - Do Fundo Partidário (arts. 38 a 44).

${ }^{9}$ Horário Gratuito de Propaganda Eleitoral, como é intitulado o acesso gratuito dos partidos políticos no rádio e na televisão. Instituído a partis da Lei 7.332 de $1^{\circ}$ de julho de 1985 , quando foram determinados os princípios fundamentais das campanhas no Brasil.

${ }^{10}$ Trata-se de pequenos comerciais de 30 ou 60 segundos inseridos em meio à programação diária das emissoras.
} 
de campanha e resultado eleitoral (BOLOGNESI e CERVI, 2011; MANCUSO, 2015); e que das motivações para investimentos de recursos financeiros em campanhas de origem partidária, pode-se apontar que essa reflete as expectativas de sucesso eleitoral em relação aos candidatos (GIBSON e RÖOMMELE, 2009), e as estratégias eleitorais dos partidos políticos de forma mais ou menos centralizada.

Dessa forma, questiona-se o quanto as organizações partidárias representam no financiamento de seus candidatos, e em consequência, o quanto esses dependem financeiramente das suas legendas e de investimentos externos, obtidos individualmente a partir de doações de pessoas físicas, jurídicas ou de recursos próprios. Na próxima seção se propõe a responder a essas questões, a partir dos casos específicos, selecionados para análise, conforme anteriormente citado.

\section{Recursos financeiros nas campanhas eleitorais brasileiras de 2012 e 2014}

O objetivo deste artigo é analisar a distribuição vertical de recursos para financiamento de campanhas eleitorais majoritárias no Brasil. Ou seja, analisar o quanto as organizações partidárias contribuem para o financiamento das atividades eleitorais das suas principais campanhas. Isso, considerando aspectos específicos do desenho institucional brasileiro, onde os partidos e as suas organizações locais têm autonomia legal para arrecadação desses recursos. A hipótese nesse sentido é que o volume de recursos financeiros investidos pelas direções partidárias nas campanhas eleitorais de seus candidatos é maior, de acordo com a avaliação das chances eleitorais dos mesmos.

Assim, candidaturas que concorrem à reeleição teriam maiores probabilidades de receber das suas agremiações maior volume de recursos financeiros para financiamento de atividades eleitorais. O que pode representar uma estratégia partidária para ampliar as vantagens das suas candidaturas, uma vez que existe, como apontado pela literatura, uma relação direta entre volume de recursos disponíveis e possibilidades de êxito eleitoral. Questiona-se também qual o grau de dependência e/ou independência financeira dos candidatos em relação aos seus partidos.

Para atender aos objetivos propostos, foram selecionados os seguintes casos: para as eleições de 2014, as duas principais candidaturas aos governos estaduais dos estados brasileiros que representam os cinco maiores colégios eleitorais do país. São eles: São Paulo, Minas Gerais, Rio de Janeiro, Bahia e Rio Grande do Sul. Para análise das eleições de 2012, foram 
selecionadas as duas principais candidaturas das capitais e principais municípios, de cada um dos estados, respectivamente: São Paulo, Belo Horizonte, Rio de Janeiro, Salvador e Porto Alegre.

O material empírico utilizado foi extraído da base de dados do TSE. Trata-se da prestação de contas eleitorais elaboradas por partidos e candidatos e entregues ao referido tribunal nos de $2012^{11}$ e $2014^{12}$, segundo critérios e prazos por esse estabelecidos. Os dados coletados foram sistematicamente organizados, de acordo com os objetivos e questionamentos específicos já citados, a que se propõe.

As primeiras tabelas apresentam os totais dos recursos financeiros que os candidatos às prefeituras das capitais brasileiras em 2012 e os candidatos aos governos estaduais tiveram disponíveis para atividades de campanha, e a porcentagem referente à participação dos partidos nesse montante. Questiona-se em quais dessas situações a participação dos partidos políticos em relação ao total arrecadado é mais significativa. O número total representa a soma dos valores destinados pelos comitês e diretórios.

Tabela 02 - Eleições 2012: Total em reais de recursos, total em reais de recursos destinados pelos partidos e percentual, por cidade e partido ${ }^{13}$

\begin{tabular}{|c|c|c|c|c|}
\hline \multirow{2}{*}{ Cidade } & \multirow{2}{*}{ Partido } & \multirow{2}{*}{ Total de Recursos } & \multicolumn{2}{|c|}{$\begin{array}{l}\text { Total de recursos investido pelo } \\
\text { partido }\end{array}$} \\
\hline & & & Absoluto & Percentual \\
\hline \multirow{2}{*}{ São Paulo } & PSDB & $33.574 .353,58$ & $31.809 .353,58$ & 94,7 \\
\hline & PT & $42.084 .066,71$ & $38.181 .736,16$ & 90,7 \\
\hline \multirow{2}{*}{ Belo Horizonte } & PSB & $21.855 .184,55$ & $15.699 .734,55$ & 71,8 \\
\hline & PT & $17.408 .279,15$ & $16.509 .395,90$ & 94,8 \\
\hline \multirow{2}{*}{ Rio de Janeiro } & PMDB & $21.208 .741,10$ & $18.792 .463,10$ & 88,6 \\
\hline & PSoL & $1.039 .561,22$ & $39.569,69$ & 3,8 \\
\hline \multirow{2}{*}{ Salvador } & DEM & $21.954 .791,70$ & $19.588 .500,00$ & 89,2 \\
\hline & PT & $15.520 .798,22$ & $10.981 .840,40$ & 70,7 \\
\hline \multirow{2}{*}{ Porto Alegre } & PCdoB & $3.916 .932,12$ & $3.014 .179,09$ & 76,9 \\
\hline & PDT & $6.247 .148,32$ & $6.093 .108,75$ & 97.5 \\
\hline
\end{tabular}

Fonte: Elaboração Própria

\footnotetext{
${ }^{11}$ Para acesso à base de dados do Tribunal Superior Eleitoral de 2012, ver: http://www.tse.jus.br/eleicoes/eleicoesanteriores/eleicoes-2012/prestacao-de-contas/prestacao-de-contas-eleicoes-2012

${ }^{12}$ Para acesso à base de dados do Tribunal Superior Eleitoral de 2014, ver: http://www.tse.jus.br/eleicoes/eleicoesanteriores/eleicoes-2014/prestacao-de-contas-eleicoes-2014/prestacao-de-contas

${ }^{13}$ Partidos relacionados: PSDB - Partido da Social Democracia Brasileira; PT - Partido dos Trabalhadores; PSB

- Partido Socialista Brasileiro; PMDB - Partido do Movimento Democrático Brasileiro; PSoL - Partido Socialismo e Liberdade; DEM - Democratas; PCdoB - Partido Comunista do Brasil; PDT Partido Democrático Trabalhista.
} 
A primeira tabela apresenta os dados das duas principais candidaturas às prefeituras das capitais dos estados selecionados para este estudo. Como pode ser observado, trata-se de 10 candidaturas de oito diferentes partidos. Sendo o PT o único a se repetir. Ao observar o percentual destinado pelos partidos para as campanhas, um primeiro padrão pode ser inferido: a considerável participação das direções partidárias como investidoras de recursos financeiros para campanhas eleitorais.

Pode-se apontar, inclusive que em 4 dos dez casos, as campanhas foram quase completamente financiadas pelos próprios partidos, o que também significa dizer que houve pouco investimento de pessoas físicas e jurídicas nas mesmas. Casos de ambos os partidos que disputaram as eleições na cidade de São Paulo, do PT em Belo Horizonte e do PDT em Porto Alegre, todos com investimento total que representa mais de $90 \%$ do total de recursos totais disponíveis para a realização da campanha. Dos seis outros casos, apenas um não apresenta um resultado expressivo, o PSoL na cidade do Rio de Janeiro. Os demais casos, acima de 70\%, um percentual consideravelmente alto.

Tabela 03 - Eleições 2014: Total em reais de recursos, total em reais de recursos destinados pelos partidos e percentual, por estado e partido ${ }^{14}$

\begin{tabular}{l|l|l|l|l}
\hline \multirow{2}{*}{ Estado } & \multirow{2}{*}{ Total de Recursos } & \multicolumn{2}{|c}{$\begin{array}{c}\text { Total de recursos investido pelo } \\
\text { partido }\end{array}$} \\
\cline { 3 - 5 } & Partido & & Absoluto & Percentual \\
\hline \multirow{2}{*}{ São Paulo } & PMDB & $29.207 .565,77$ & $9.836 .000,00$ & 33,6 \\
\hline \multirow{2}{*}{ Minas Gerais } & PSDB & $40.394 .953,03$ & $39.047 .223,51$ & 96,6 \\
\hline \multirow{2}{*}{ Rio de Janeiro } & PSDB & $40.398 .648,82$ & $33.189 .250,00$ & 82,1 \\
\cline { 2 - 5 } & PT & $53.413 .190,03$ & $39.252 .449,03$ & 73,4 \\
\hline \multirow{2}{*}{ Bahia } & PMDB & $45.150 .556,49$ & $44.066 .453,57$ & 97,5 \\
\cline { 2 - 5 } & PRB & $6.669 .257,59$ & $2.594 .042,84$ & 38,8 \\
\hline \multirow{2}{*}{ Rio Grande Do Sul } & DEM & $21.657 .630,34$ & $15.338 .436,67$ & 70,8 \\
\cline { 2 - 5 } & PT & $32.196 .722,63$ & $19.260 .026,08$ & 59,8 \\
\cline { 2 - 5 } & PMDB & $10.835 .891,18$ & $7.393 .391,18$ & 68,2 \\
\hline
\end{tabular}

Fonte: Elaboração Própria

Para as eleições gerais de 2014, foram selecionadas as duas principais candidaturas aos governos dos estados de maior colégio eleitoral no Brasil. Quando comparado ao caso anterior, tem-se um menor número de partidos, apenas cinco e a repetição de três legendas: PMDB, PSDB e PT. Assim como no caso anterior, pode-se observar que os partidos contribuíram

${ }^{14}$ Partidos relacionados: PRB - Partido Republicano Brasileiro. 
consideravelmente para as campanhas de seus candidatos. Em dois dos 10 casos, mais de $90 \%$ do total de recursos, teve origem dos próprios partidos, PSDB em São Paulo, e o PMDB no Rio de Janeiro. Há mais casos em que os percentuais estão entre 30 e 70\%, entretanto, em nenhuma campanha pode-se afirmar que a contribuição partidária foi irrelevante.

Tem-se que as primeiras tabelas apresentaram o total de recursos em reais destinados pelos partidos aos candidatos às capitais brasileiras em 2012 e ao governo dos estados em 2014. Entretanto, a distribuição vertical de recursos pode acorrer a partir dos diferentes níveis de organização de cada uma das legendas: nacional, estadual e municipal. Como observado na seção anterior, no Brasil as organizações partidárias se organizam nos três níveis que compõem a federação e, apesar de determinada unidade institucional, em períodos eleitorais os partidos tem autonomia legal, salvo constrangimentos internos, para captação de recursos financeiros.

A distribuição de recursos pelas organizações partidárias se dá de forma assimétrica. Disso infere-se que, primeiro, campanhas podem receber recursos financeiros dos diferentes "núcleos" do mesmo partido (nacional, estadual e municipal), e que esses núcleos investem recursos financeiros em determinadas campanhas e não em outras. Essa escolha é fruto de estratégias eleitorais racionalmente orientadas, a partir de uma avaliação de custos e benefícios. Em outras palavras, o volume de recursos investidos, pode apontar para as expectativas eleitorais que a organização partidária tem sobre determinada campanha.

Para finalidade de prestação de contas eleitorais, o TSE estabelece modalidades de repasse de recursos. São elas: Direção Nacional (DN); Direção Estadual/Distrital (DED), Direção Municipal (DM); Comitê Financeiro Único (CFU); Comitê Financeiro Nacional para Presidente da República (CFNPR), Comitê Financeiro Distrital/Estadual para Governador (CFDEG), Comitê Financeiro Municipal Único (CFMU), Comitê Financeiro Municipal para Prefeito (CFMP), Comitê Financeiro Municipal para Vereador (CFMV).

De acordo com o artigo 19 da Lei $\mathrm{n}^{\circ}$ 9.504/1997, os partidos devem constituir comitês financeiros para arrecadar e destinar recursos para campanhas eleitorais. Esse é dispositivo criado pela justiça eleitoral para auxiliar partidos e candidatos na prestação de contas eleitorais. Os partidos podem escolher pela composição de um comitê financeiro único, que concentra todas as atividades de gestão dos recursos, tais como abertura de conta bancária e a administração de recibos, ou a criação de um comitê financeiro para cada disputa eleitoral. As duas próximas tabelas apresentam o percentual de recursos financeiros destinados pelos diferentes núcleos de cada um dos partidos, em relação ao total destinado pelos mesmos. 
Tabela 04- Eleições 2012: Percentual destinado pelos núcleos partidários, por cidade e partido

\begin{tabular}{l|l|l|l|l|l|l|l}
\hline \multirow{2}{*}{ Cidade } & \multirow{2}{*}{ Partido } & \multicolumn{7}{|c}{ Núcleos Partidários } \\
\cline { 3 - 9 } & & DN & DED & DM & CFMU & CFMP & CFMV \\
\hline \multirow{2}{*}{ São Paulo } & PSDB & & & & & 97,9 & 2 \\
\cline { 2 - 9 } & PT & 35,9 & 0,5 & & 63,4 & & 0,2 \\
\hline \multirow{2}{*}{ Rio de Janeiro } & PMDB & 17 & 0,1 & & 82,8 & & \\
\cline { 2 - 9 } & PSOL & & 100 & & & & \\
\hline \multirow{2}{*}{ Belo Horizonte } & PSB & 66,9 & & 9,8 & & 19,7 & 3,5 \\
\cline { 2 - 9 } & PT & 85,1 & 14,1 & 0,2 & & 0,4 & \\
\hline \multirow{2}{*}{ Porto Alegre } & DEM & 98,2 & 1,7 & & & & \\
\cline { 2 - 9 } & PT & 96,6 & 3,7 & & & & \\
\cline { 2 - 9 } & PCdoB & 72,9 & 11 & 6,2 & 9,7 & & \\
\hline
\end{tabular}

Fonte: Elaboração Própria

Por fatores já explanados, as eleições para prefeitura no Brasil são de grande importância para os partidos políticos, principalmente quando se trata das principais capitais do país. Essa pode ser uma das explicações para os dados da tabela 4, que mostram primeiro, a importância dos diretórios nacionais em 7 dos dez casos. Segundo, pode-se apontar para uma determinada dependência financeira das organizações partidárias locais em relação às nacionais em períodos eleitorais e, finalmente, pode-se enfatizar a importância das eleições para os partidos.

Também pode ser observada a participação dos diretórios estaduais, mas com menor importância, a não ser pelo caso do PSoL no Rio de Janeiro, que contou com 100\% dos recursos partidários destinados por esse diretório. Por fim, pode-se destacar a capacidade de cinco das 10 capitais com maior parte dos recursos de origem municipal: PT de São Paulo, PMDB do Rio de Janeiro e o PDT de Porto Alegre, por meio do CFMU; PSDB de São Paulo e PSB de Belo Horizonte, pelo CFMP.

\begin{tabular}{l|l|l|l|l|l|l}
\multicolumn{7}{c}{ Tabela 05- Eleições 2014: Percentual destinado pelos núcleos } \\
partidários, por estado e partido \\
\hline \multirow{2}{*}{ Estado } & \multirow{2}{*}{ Partido } & \multicolumn{5}{c}{ Núcleos Partidários } \\
\cline { 3 - 8 } & & DN & DED & CFU & CFNPR & CFDEG \\
\hline \multirow{2}{*}{ São Paulo } & PMDB & 61,3 & 38,6 & & & \\
\cline { 2 - 8 } & PSDB & & & & & 100 \\
\hline \multirow{2}{*}{ Rio de Janeiro } & PMDB & & 0,6 & 99,3 & & \\
\cline { 2 - 8 } & PRB & 52,6 & 47,3 & & & \\
\hline \multirow{2}{*}{ Minas Gerais } & PSDB & 30,1 & 60,08 & & 9 & \\
\cline { 2 - 8 } & PT & 35,4 & 2,9 & 61,5 & & \\
\hline \multirow{2}{*}{ Bahia } & DEM & 84 & 14,6 & & 1,3 & \\
\cline { 2 - 8 } & PT & 34 & 65,9 & & & \\
\multirow{2}{*}{ Rio Grande do Sul } & PMDB & 2,4 & 0,6 & 97,4 & & \\
\cline { 2 - 8 } & PT & 28,8 & 71,1 & & & \\
\hline
\end{tabular}

Fonte: Elaboração Própria 
A partir dos dados da tabela cinco, pode ser indicado que existe uma dependência das direções nacionais dos partidos, de forma pouco menos acentuada se comparado ao caso anterior, entretanto significativa. Nesse caso, as candidaturas contaram também com os recursos destinados pelas organizações estaduais e pelos comitês de campanha, em quatro dos 10 casos apresentados, e aqui pode ser destacado o caso do PSDB paulista que contou com $100 \%$ dos recursos partidários oriundos do comitê específico para a campanha do governo do estado.

Existe um problema a ser esclarecido quanto à fonte. Ainda que grande parte dos recursos financeiros concentrados pelos partidos tenha origem no fundo partidário, existem outras fontes, como a doação de filiados, de ocupantes de cargos eletivos, de pessoas físicas e jurídicas, e de pessoas envolvidas de alguma forma aos partidos. Assim, mesmo o dinheiro destinado pelo partido para as campanhas pode ter origens diversas. $\mathrm{O}$ caso dos comitês financeiros são exemplos claros. Indica-se que é coerente enquadrar esse tipo de recurso como originário dos partidos, porque é nele que está concentrada toda a sua gestão, incluso, a distribuição.

A hipótese central deste trabalho indica que o volume de recursos financeiros investidos pelas direções partidárias nas campanhas eleitorais de seus candidatos é maior de acordo com a avaliação das chances eleitorais dos mesmos. Assim candidatos governistas recebem mais dinheiro de suas legendas se comparados aos candidatos opositores. Para testá-la, então, as próximas tabelas apresentam o percentual total investido pelos partidos, em relação ao total geral de recursos disponíveis e a posição de cada uma das candidaturas em relação ao governo municipal e estadual. Com destaque para o partido vencedor em cada uma das cidades e estados.

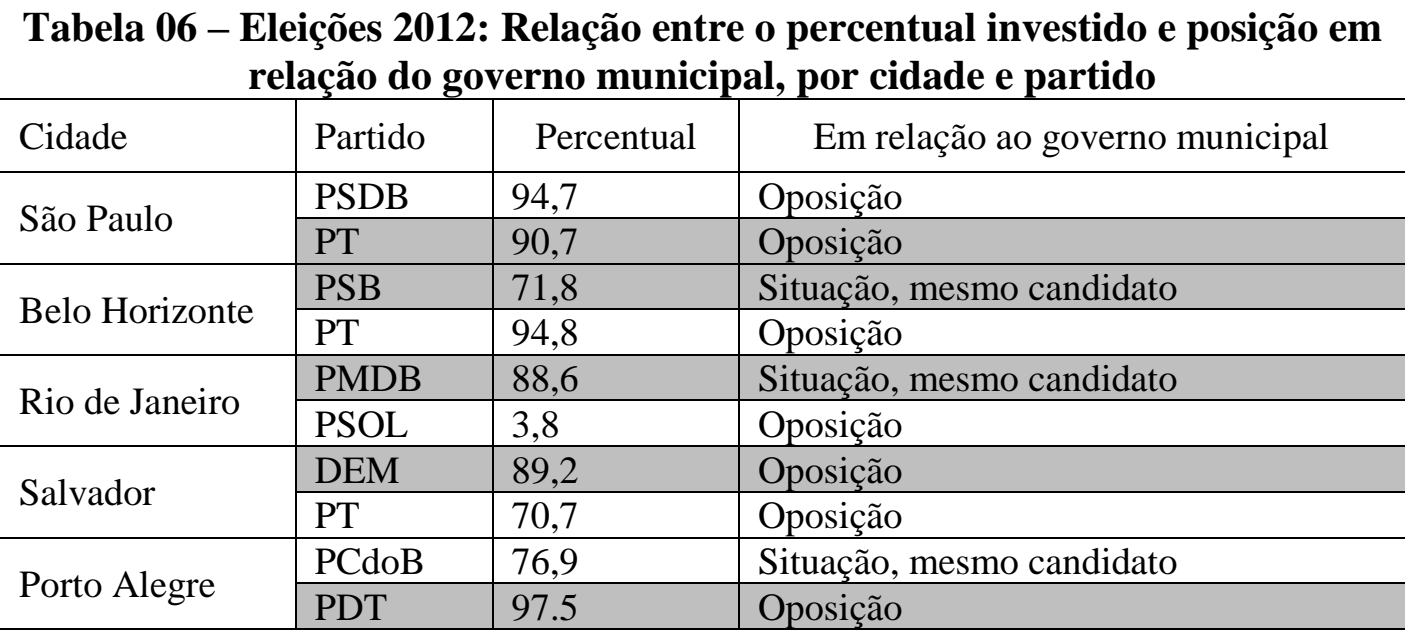

Fonte: Elaboração Própria 
A partir dos dados demonstrados na sexta tabela, pode-se afirmar que os partidos de situação receberam um maior volume de recursos se comparado aos de oposição. A média para o primeiro caso é 79,1 e no segundo, de 73,9. Entretendo, essa diferença não é suficiente para indicar a validade da hipótese ressaltada. Ou seja, no caso das eleições municipais de 2012 para as principais campanhas das capitais selecionadas, não há relação direta consistente entre a posição do partido em relação ao governo municipal e o total de dinheiro destinado a ele pelo partido.

\begin{tabular}{l|l|l|l}
\multicolumn{4}{c}{$\begin{array}{c}\text { Tabela 07 - Eleições 2014: Relação entre o percentual investido e posição em } \\
\text { relação do governo estadual, por estado e partido }\end{array}$} \\
\hline \multirow{2}{*}{ Estado } & Partido & Percentual & \multicolumn{1}{c}{ Em relação ao governo estadual } \\
\hline \multirow{2}{*}{ São Paulo } & PMDB & 33,6 & Oposição \\
\cline { 2 - 4 } & PSDB & 96,6 & Situação, mesmo candidato \\
\hline \multirow{2}{*}{ Minas Gerais } & PSDB & 82,1 & Situação, outro candidato \\
\cline { 2 - 4 } & PT & 73,4 & Oposição \\
\hline \multirow{2}{*}{ Rio de Janeiro } & PMDB & 97,5 & Situação, outro candidato \\
\cline { 2 - 4 } & PRB & 38,8 & Oposição \\
\hline \multirow{2}{*}{ Bahia } & DEM & 70,8 & Oposição \\
\cline { 2 - 4 } & PT & 59,8 & Situação, mesmo candidato \\
\hline \multirow{2}{*}{ Rio Grande do Sul } & PMDB & 68,2 & Oposição \\
\cline { 2 - 4 } & PT & 37,8 & Situação, mesmo candidato \\
\hline
\end{tabular}

Fonte: Elaboração Própria

Para as eleições de 2014, diferente do caso anterior, existe uma diferença significativa entre as médias dos percentuais investidos pelos partidos nas campanhas dos governadores estaduais. Para os partidos de situação, essa média é de 74,7, enquanto que para os partidos de oposição, a média é de 56,9. Consideravelmente inferior se comparados.

Quanto à proporção do investimento partidário bem sucedido, a média de recursos investidos entre os partidos que venceram seus adversários é consideravelmente maior, tanto para as eleições municipais, quanto para as eleições nos estados. Para 2012, a média de recursos investidos pelos partidos políticos que venceram as eleições é de 85 , enquanto a média dos partidos que foram derrotados é de 68,1. Em 2014, a média entre os vencedores é de 79,1 e dos demais, 52,6.

\section{Considerações finais}

O primeiro padrão encontrado é referente à partição dos partidos políticos nas campanhas dos seus candidatos quanto ao investimento financeiro em ambos os casos analisados: para as eleições para o governo dos estados e para as prefeituras das suas respectivas 
capitais. Pode-se observar que há determinada dependência financeira desses candidatos em relação aos seus partidos, ao passo que outras fontes de recursos possíveis - com exceção única ao caso do PSoL, como demonstrado na tabela 02 - significaram muito pouco do total geral de recursos. Ainda que haja uma menor concentração desse tipo de recurso nas eleições de 2014, é possível argumentar que para ambos os pleitos a distribuição vertical de recursos financeiros foi essencial.

Olhando para os números de forma desagregada pode ser inferido que para as eleições municipais existe uma maior dependência financeira das organizações partidárias nacionais e a nível local, com exceção novamente do PSoL, e menor participação dos diretórios estaduais. Para os governos, a participação do partido é relevante principalmente nos diretórios nacionais e estaduais, mas também existe uma participação significativa em alguns casos dos comitês financeiros.

Os comitês financeiros são instituídos pelos partidos com finalidade de gerenciar recursos de campanha. A participação relevante desse órgão no montante de recursos arrecadados pode representar uma maior capacidade dos partidos de angariar recursos nos seus redutos eleitorais. Características dos contextos políticos locais conferem força a esse argumento, uma vez que esse dado pode ser observado em contextos onde o partido tradicionalmente estrutura competição eleitoral. São os casos de: PT e PSDB na cidade de São Paulo; PSDB e PMDB nos Estados de São Paulo e Rio de Janeiro.

Uma vez ressaltado o argumento da importância da disponibilidade de recursos financeiros para as campanhas no Brasil, é possível indicar que os partidos políticos brasileiros se voltam estrategicamente para eleições governamentais e municipais, ainda que os candidatos a prefeitos dependam mais do que os candidatos ao governo dos estados. Em outras palavras existe um grau de concentração de recursos nos dois conjuntos de dados apresentados, ainda que para o primeiro - eleições municipais - essa concentração seja mais acentuada.

O percentual de recursos investidos pelos partidos para as eleições é bastante alto para as eleições de 2012 e 2014. Em relação à primeira, a posição do partido em relação ao governo municipal, situação ou oposição, não pode ser considerada uma variável que interfere diretamente no montante de recursos financeiros destinados pelos partidos. Em outros termos, não é possível indicar a validade da hipótese levantada, que relaciona volume de recursos e avaliação das chances eleitorais, partindo do princípio da reeleição. 
Entretanto, para as eleições de 2014 a diferença das médias de recursos investidos pelos partidos para as campanhas de seus candidatos é considerável. Ou seja, candidatos governistas receberam maior volume de recursos financeiros de seus partidos, quando comparados aos oposicionistas. O que pode sugerir uma relação entre volume de recursos financeiros investidos pelas direções partidárias e a avaliação das chances eleitorais dos seus candidatos, associado as estratégias eleitorais.

Como destacado, o financiamento das campanhas eleitorais no Brasil é misto. O que significa que partidos e candidatos podem reunir recursos a partir da doação de pessoas físicas, jurídicas, de recursos próprios e do investimento dos partidos políticos. Como foi possível observar, existe um padrão na distribuição de recursos partidários para as eleições majoritárias no Brasil e, de acordo com os objetivos inicialmente propostos, essa pode ser considerada a principal conclusão alcançada.

Das demais: há maior dependência financeira dos municípios e a maior capacidade das candidaturas aos governos estaduais na arrecadação de recursos; o mesmo partido não investe de forma semelhante nas candidaturas dos diferentes estados e municípios. Esse investimento depende de algumas características locais como, por exemplo, no caso de 2014, a posição do partido em relação ao governo; e que há relação entre volume de investimento financeiro e sucesso eleitoral.

Apesar de se tratar de um estudo que privilegiou determinados casos - as duas principais candidaturas aos governos estaduais dos estados brasileiros que representam os cinco maiores colégios eleitorais do país, e as duas principais candidaturas das respectivas capitais - chega-se a importantes conclusões que contribuem para os estudos que buscam relacionar o financiamento partidário para eleições majoritárias e a organização dos partidos políticos às estratégias eleitorais dos mesmos.

\section{Referências bibliográficas}

ANDERSON, George. Federalismo: Uma introdução. Tradução Ewandro Magalhães Jr., Fátima Guerreiro. Rio de Janeiro: Ed. FGV, 2009.

ALVES, M. "Partidos políticos e campanhas profissionais as eleições municipais de Sorocaba em 2012”. In: VI Compolítica (Congresso da Associação Brasileira de Pesquisadores em Comunicação e Política). Rio de janeiro, 2015.

BRAGA, Maria do Socorro Sousa; PAIVA, Denise; PIMENTEL, Jorge Tadeu P. JR. "Eleitorado e Partidos Políticos no Brasil". Opinião Pública, Campinas, vol. 13, no 2, nov, 2007, p.388-408. 
BOLLEYER, N. "New party organization in Western Europe: Of party hierarchies, stratarchies and federations". Party Politics, 18(3), 2012, pp 315-336.

BOLOGNESI, B; CERVI, E. "Distribuição de recursos e sucesso eleitoral nas eleições 2006: Dinheiro e tempo de HGPE como financiadores de campanha a deputado federal do Paraná". In: $3^{\circ}$ Encontro anual da Anpocs (Associação Nacional de Pós-Graduação e Pesquisa em Ciências Sociais), Caxambu-MG, 2011.

CARTY, K. "Parties as franchise systems. The stratarchial organizational imperative". Party Politics, 10(1), 2004, pp5-24.

CHANDLER, W; CHANDLER, M. "Federalism and Political Parties". Europen Journal of Political Economy, London: Sage, 3(1-2), 1987, pp.87-79.

CARREIRÃO, Y. d. "O sistema partidário brasileiro: um debate com a literatura recente". Revista Brasileira de Ciência Política (14), 2014, pp. 255-295.

DANTAS, H. Coligações em eleições majoritárias municipais: a lógica no alinhamento dos partidos políticos brasileiros nas disputas de 2000 e 2004. $176 \mathrm{f}$. Tese (Doutorado) - Faculdade de Filosofia, Letras e Ciências Humanas, Universidade de São Paulo, São Paulo, 2007.

FARRELL, David M. "Campaign Strategies and Tactics" In: LEDUC, L; NIEMI, R.G; NORRIS, P; (eds), Comparing Democracies, Thousand Oaks, Calif.: Sage, 1996.

GIBSON, R.; ROMMELLE, A. "Mensuring the profissionalization of political campaigning". Party Politics, v. 15. n3, 2009.

GUARNIERI, F. H. E. "A força dos partidos 'fracos"”. Dados, Rio de Janeiro, v. 54, 2011, p. 235-258.

NICOLAU, Jairo. Sistemas eleitorais. 6.ed. Rio de Janeiro: Ed FGV. 2012

KERBAUY, M. T. M. "Federalismo, descentralização e democracia". Estudos de Sociologia, Araraquara, v. 6, n. 10., 2001

MANCUSO. W. "Investimento eleitoral no Brasil: balanço da literatura (2001-2012) e agenda de pesquisa”. Revista de Sociologia Política, Curitiba, v.23 n.54, 2015.

MELO, M. A; PEREIRA, C. Making Brazil Work: Checking the President in a Multiparty System. New York: Palgrave Macmillan, 2013.

SAMUELS, D., \& SHUGART, M. Presidents, Parties, and Prime Ministers: How the Separation of Powers Affects Party Organization and Behavior. Cambridge: Cambridge University Press, 2010.

SPECK, Bruno Wilhelm. "O financiamento de campanhas". In. AVRITZER, L; ANASTASIA, F. (orgs) Reforma política no Brasil. Belo Horizonte: Ed. UFMG, 2006. 
“O financiamento político e a corrupção no Brasil”. In: Rita de Cassia Biason. (Org.). Temas de corrupção política no Brasil. 1ed.São Paulo: Balão Editorial, v. 1, 2012, p. 49-97.

TELLES, Helcimara de S; LOURENÇO, L. C.; STORNI, T. P. "Partido, campanha e voto: como o eleitor decide nas municipais". Revista Sociedade e Cultura, Goiás, v. 12, n.1, 2009.

VEIGA, Luciana. "Em busca das razões do voto: o uso que o eleitor faz da propaganda política". Contra campo, V. 7 n.0, 2010, p.183-208.

Recebido em: Maio de 2016 Aceito em: Dezembro de 2016 